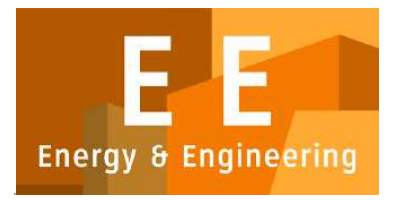

PAPER - OPEN ACCESS

\title{
Kajian Teoritis: Pariwisata Berkelanjutan berdasarkan Distinctiveness
}

$\begin{array}{ll}\text { Author } & : \text { Nurlisa Ginting dkk., } \\ \text { DOI } & : 10.32734 / \text { ee.v3i1.870 } \\ \text { Electronic ISSN } & : 2654-704 X \\ \text { Print ISSN } & : 2654-7031\end{array}$

Volume 3 Issue 1-2020 TALENTA Conference Series: Energy \& Engineering (EE)

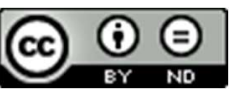

This work is licensed under a Creative Commons Attribution-NoDerivatives 4.0 International License.

Published under licence by TALENTA Publisher, Universitas Sumatera Utara

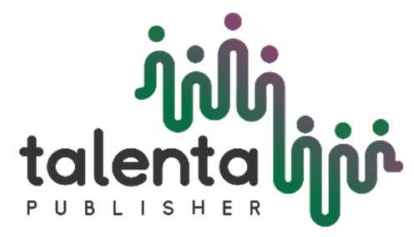




\title{
jibiti

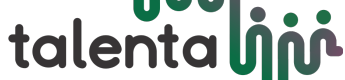 \\ EE Conference Series 03 (2020) \\ TALENTA Conference Series
}

P U B L I S HER
Available online at https://talentaconfseries.usu.ac.id/ee

\section{Kajian Teoritis: Pariwisata Berkelanjutan berdasarkan Distinctiveness} Theoretical Study: Sustainable Tourism based on Distinctiveness

\author{
Nurlisa Ginting ${ }^{1,2,3}$, Recrisa Lathersia ${ }^{1}$, Riris Adriaty Putri ${ }^{1}$, Munazirah $^{1 *}$, Putri Ayu \\ Dirgantara Yazib ${ }^{1}$, Annisa Salsabilla ${ }^{1}$ \\ ${ }^{\text {I} P r o g r a m ~ S t u d i ~ T e k n i k ~ A r s i t e k t u r, ~ F a k u l t a s ~ T e k n i k, ~ U n i v e r s i t a s ~ S u m a t e r a ~ U t a r a, ~ J a l a n ~ P e r p u s t a k a a n ~ G e d u n g ~ J 7 ~ K a m p u s ~ U S U, ~ M e d a n, ~ 20155, ~}$ \\ Indonesia \\ ${ }^{2}$ Kelompok Kerja Pariwisata Kawasan Danau Toba dan Pariwisata Berkelnajutan, Universitas Sumatera Utara, Jalan Dr. Mansyur Kampus USU, \\ Medan, 20155, Indonesia \\ ${ }^{3}$ Monitoring Centre for Sustainable Tourism Observatory (MCSTO) Universitas Sumatera Utara, Jalan Perpustakaan Gedung J7 Kampus USU, \\ Medan, 20155, Indonesia
}

nurlisa@usu.ac.id, lathersiarecrisa@gmail.com,priris02@gmail.com,mzirah20@gmail.com, tarafiaj@gmail.com, cut.aisyah714@gmail.com

\begin{abstract}
Abstrak
Pariwisata merupakan faktor penting dalam membentuk identitas pada suatu kawasan. Pariwisata berkelanjutan sendiri merupakan pariwisata yang memperkirakan dampak ekonomi, lingkungan, serta sosial budaya untuk masa yang akan datang. Kekahasan suatu kawasan pariwisata dapat menambah nilai dan kesan baik terhadap wisatawan. Penjualan produk - produk lokal kepada wisatawan juga dapat menurunkan angka kemiskinan masyarakat lokal. Oleh sebab itu keterkaitan antara pariwisata dan distinctiveness sangatlah signifikan karena kekhasan lokal yang dapat menghidupkan pariwisata kawasan sehingga dapat terus dikunjungi oleh wisatawan. Tujuan dari penelitian ini adalah untuk menemukan teori keterkaitan antar pariwisata berkelanjutan dan distinctiveness. Metode yang digunakan pada penelitian ini adalah tinjauan literatur teoritis yang berfokus pada kumpulan teori yang telah ditemukan pada penelitian sebelumnya kemudian mencari keterkaitan di antara teori-teori tersebut untuk mengembangkan sebuah teori baru. Berdasarkan hasil kajian teori ditemukan tiga aspek pariwisata berkelanjutan yaitu ekonomi, lingkungan, dan sosial budaya yang berdasarkan pada empat elemen distinctiveness yaitu landmark, keunikan, karakterter tertentu dan perbedaan persepsi.
\end{abstract}

Kata kunci: Pariwisata Berkelanjutan, Distinctiveness

\begin{abstract}
Tourism is an important factor in shaping the identity of an area. Sustainable tourism itself is tourism that estimates the economic, environmental and socio-cultural impacts for the future. The particularity of a tourism area can add value and a good impression on tourists. Sales of local products to tourists can also reduce poverty rates for local people. Therefore the link between tourism and distinctiveness is very significant because of the local uniqueness that can revive regional tourism so that it can continue to be visited by tourists. The purpose of this study is to find a theory of the relationship between sustainable tourism and distinctiveness. The method used in this study is a review of theoretical literature that focuses on a collection of theories that have been found in previous studies and then look for links between these theories to develop a new theory. Based on the results of the theoretical study, three aspects of sustainable tourism are found, namely economic, environmental, and socio-cultural based on four distinctiveness elements namely landmarks, uniqueness, certain characteristics and differences in perception.
\end{abstract}

Keywords: Sustainable Tourism, Distinctiveness

(C) 2020 The Authors. Published by TALENTA Publisher Universitas Sumatera Utara Selection and peer-review under responsibility of Seminar Nasional Kearifan Lokal V 2020 p-ISSN: 2654-7031, e-ISSN: 2654-704X, DOI: 10.32734/ee.v3i1.870 


\section{Pendahuluan}

Saat ini lingkungan pariwisata tengah saling bersaing satu sama lain agar dapat menjadi destinasi wisata yang paling menarik, juga sebagai tempat kerja, lingkungan yang kaya akan budaya, dan lain - lain [1]. Pariwisata merupakan simbol yang dapat membantu dalam membangun dan menyampaikan rasa identitas nasional [2]. Pariwisata merupakan faktor penting dalam proses pembangunan identitas. Selain memiliki kekhasan sebagai penambahan nilai kawasan, pariwisata juga dianggap sebagai langkah yang efisien untuk menurunkan kemiskinan di beberapa masyarakat tradisional. Pariwisata menyediakan lapangan pekerjaan yang berbeda dari mata pencaharian tradisional. Pariwisata juga dapat dijadikan sarana untuk memperjual - belikan produk lokal. Dapat disimpulkan bahwa kekhasan lokal lah yang menghidupkan kawasan pariwisata agara kawasan tersebut secara terus menerus dikunjungi oleh wisatawan. Pariwisata berkelanjutan dapat didefinisikan sebagai pariwisata yang memperhitungkan sepenuhnya dampak sosial, lingkungan dan ekonomi baik saat ini maupun masa depan, menangani kebutuhan pengunjung, industri, lingkungan dan masyarakat lokal [3]. Prinsip keberlanjutan mengacu pada aspek lingkungan, ekonomi, dan sosial budaya dari pengembangan pariwisata, dan keseimbangan yang sesuai harus ditetapkan antara ketiga dimensi ini untuk menjamin keberlanjutan jangka panjangnya [4]. Konsep pariwisata berkelanjutannyalah yang dapat membantu meningkatkan kualitas hidup masyarakat dan mampu menjaga kualitas lingkungan wisatawan lokal [5]. Berdasarkan teori tersebut pariwisata berkelanjutan adalah sebuah konsep wisata yang berusaha membuat dampak positif terhadap lingkungan, masyarakat, dan ekonomi. Pariwisata berkelanjutan juga merupakan sektor pariwisata yang mengedepankan aspek wisata alam, budaya, dan juga edukasi serta mendorong pemeliharaan alam dan juga lingkungan yang terdapat di dalamnya.

Terdapat empat elemen identitas tempat yang telah dikaji pada penetlitain sebelumnya yaitu Distinctiveness, Continuity, Self-Esteem, dan Self Efficacy [6]. Diantara elemen-elemen identitas tempat yang telah dikemukakan sebelumnya, salah satu aspek identitas tempat itu digunakan untuk menunjuang pariwisata berkelanjutan ini yaitu distinctiveness. Distinctiveness merupakan aspek penting dalam mengembangkan keunikan suatu tempat [7]. Distinctiveness mengacu pada wilayah atau tempat yang dapatdibedakan dari tempat dan atau kota lainnya [6]. Suatu wilayah atau daerah yang memiliki keunikan akan membuat tempat itu lebih mudah dikenali daripada tempat lainnya [8]. Distinctiveness merupakan aspek penting dalam mengembangkan keunikan suatu tempat [7]. Kekhasan dapat membuat orang merasakan pengalaman yang berbeda di setiap destinasi yang dikunjunginya [6]. Pengalaman dari distinctiveness dapat menciptakan reaksi emosional dan psikologi antara turis dan tempat [1]. Apabila sebuah kawasan tidak memiliki kekhasan atau karakter, maka kawasan ini akan terkesan membosankan dan mungkin saja dilupakan. Tetapi apabila sebuah kawasan menarik dan mudah dikenali, kekhasan atau karakteristik tertentu pada kawasan tersebut akan membedakannya dengan kawasanlain.

Pentingnya keterkaitan antara pariwisata berkelanjutan dan distinctiveness dimana kekhasan dapat meningkatkan daya tarik dan daya saing suatu destinasi/wisata terutama karena wisatawan lokal maupun internasional semakin mencari pengalaman perjalanan wisata yang unik dan bermakna untuk memenuhi kebutuhan dan kepuasan mereka [9]. Oleh karena itu, langkah pertama yang di perlukan untuk strategi pemasaran tempat yang dapat mendorong wisatawan untuk memilihnya sebagai tujuan ialah dengan mengidentifikasi elemen-elemen unik dan berbeda dari destinasi [10]. Berdasarkan beberapa teori pariwisata berkelanjutan dan distinctiveness tersebut keterkaitan antar keduanya sangat mempengaruhi perkembangan pariwisata berkelanjutan dan seberapa berpengaruhnya aspek distinctiveness dalam pengembangannya. Maka dari itu kajian ini penting untuk dilakukan dengan tujuan menemukan teori keterkaitan pariwisata berkelanjutan dandistinctiveness.

\section{Pariwisata Berkelanjutan}

Menurut Middleton terdapat lima komponen pariwisata yaitu atraksi dan lingkungan destinasi, fasilitas dan layanan destinasi, aksesibilatas destinasi, image destinasi, dan harga untuk konsumen [11]. Pariwisata berkelanjutan dapat didefinisikan sebagai pariwisata yang memperhitungkan sepenuhnya dampak sosial, lingkungan dan ekonomi baik saat ini maupun masa depan, menangani kebutuhan pengunjung, industri, lingkungan dan masyarakat lokal. Oleh karena itu, ada beberapa hal yang harus diperhatikan dalam pengembangan pariwisata berkelanjutan yaitu, (1) menghormati keaslian sosial-budaya masyarakat tuan rumah, melestarikan warisan budaya dan nilai-nilai tradisional yang dibangun dan hidup, 
serta berkontribusi pada pemahaman dan toleransi antar budaya, (2) memanfaatkan sumber daya lingkungan secara optimal yang merupakan elemen kunci dalam pengembangan pariwisata, mempertahankan proses ekologis yang penting dan membantu melestarikan warisan alam dan keanekaragaman hayati, (3) memastikan operasi ekonomi jangka panjang yang layak, hal ini berkaitan terhadap pemberian kesempatan kerja yang stabil terhadap masyarakat didaerah destinasi dan peluang memperoleh tambahan penghasilan dari setiap aktivitas pariwisata yang dilakukan. Mencapai pariwisata berkelanjutan adalah proses yang berkelanjutan dan membutuhkan pemantauan dampak yang konstan, memperkenalkan langkah-langkah pencegahan dan/atau perbaikan yang diperlukan kapan pun diperlukan. Pariwisata berkelanjutan juga harus menjaga tingkat kepuasan wisatawan yang tinggi dan memastikan pengalaman yang berarti bagi para wisatawan, meningkatkan kesadaran mereka tentang masalah keberlanjutan dan mempromosikan praktik pariwisata berkelanjutan diantara mereka [4].

Konsep berkelanjutan dapat membantu meningkatkan kualitas hidup masyarakat dan juga mampu menjaga kualitas lingkungan wisatawan lokal [5]. Pengembangan pariwisata perlu direncanakan dengan hati-hati dan penuh dengan persiapan, sehingga dapat memeperpanjang dan memanfaatkan siklus hidupnya [12]. Pengembangan pariwisata berkelanjutan tidak hanya berfokus pada peningkatan jumlah wisatawan tetapi juga harus mempertimbangkan keseimbangan aspek lingkungan dan sosial budaya, ketiga komponen tersebut harus seimbang untuk mencapai keberlanjutan [13]. Faktanya pariwisata berkelanjutan bukanlah hanya sekedar produk dari pariwisata tetapi berubah menjadi hal yang harus dicapai dalam pengembangan pariwisata [14]. Terdapat dua faktor utama yang harus diperhatikan dalam hal keberlanjutan yaitu faktor ekologis keanekaragaman hayati dan kemampuan jangka panjang sistem ekologi global untuk mempertahankan diri. Sedangkan perspektif lain digambarkan sebagai 'etis'. Ini menyangkut karakter moral yang memotivasi banyak dorongan untuk keberlanjutan [15].

Beberapa penelitian yang telah dilakukan sebelumnya dan terdapat beberapa prinsip pengembangan pariwisata berkelanjutan yaitu aspek lingkungan [13] [16], aspek ekologis [17], dimana pendidikan serta pelatihan yang seharusnya dilakukan untuk meningkatkan pengelolaan pariwisata lokal yang melindungi lingkungan dan alam [18], aspek ekonomi [13] [16] [17], dimana pariwisata juga harus menyediakan pekerjaan bagi masyarakat untuk meningkatkan kesejahteraan mereka [18] dan memiliki manajemen pariwisata yang baik [13], aspek sosial budaya[13] [16] [17], dimana masyarakat setempat yang mengelola kegiatan pariwisata di daerah mereka [18], dan menggunakan standar internsional sebagai referensi [18]. Dari beberapa pembahasan mengenai prinsip-prinsip pariwisata berkelanjutan tersebut dapat disimpulkan bahwa aspek-aspek yang paling menonjol apabila kawasan wisata tersebut merupakan pariwisata bekelanjutan adalah (1) aspek ekonomi, (2) aspek lingkungan, dan (3) aspek sosial budaya.

\section{Distinctiveness}

Distinctiveness merupakan bagian penting dalam salah satu aspek yang membentuk identitas pada kawasan atau tempat [19]. Karakteristik yang khas merupakan dasar dari identifikasi sosial [8]. Orang yang tinggal di berbagai tempat yang berbeda (berdasarkan fisik ataupun budaya) cendurung membandingkan satu tempat dengan tempat yang lainnya dan lebih banyak menunjukkan identifikasi tempat [8]. Oleh karena itu, dapat kita lihat bahwa karakteristik suatu tempat erat kaitannya dengan konteks sosial. Selain itu, karakteristik tempat juga sudah seharusnya berbeda dengan karakteristik tempat lain. Hal ini agar memudahkan untuk membedakan antara satu kawasan dengankawasan yang lainnya. Suatu tempat dikatakan memiliki identitas apabila tempat tersebut mempunyai kekhasan atau keunikan yang dapat membedakannya dari tempat yang lain [6]. Elemen-elemen yang membentuk distinctiveness akan menghasilkan keunikan atau karakteristik tertentu dari sebuah kawasan. Apabila sebuah kawasan tidak memiliki kekhasan atau karakter, maka kawasan ini akan terkesan membosankan dan mungkin saja dilupakan. Tetapi apabila sebuah kawasan menarik dan mudah dikenali, kekhasan atau karakteristik tertentu pada kawasan tersebut akan membedakannya dengan kawasan lain. Kekhasan atau karakteristik tertentu suatu kawasan dapat kita lihat dari aktivitas budaya yang terjadi, produk lokal, transportasi, dan bangunannya. Tempat dapat menjadi komponen yang membedakan satu orang dengan orang lain. Kekhasan dapat membuat orang merasakan pengalaman yang berbeda di setiap destinasi yang dikunjunginya [6]. Pengalaman dari distinctiveness dapat menciptakan reaksi emosional dan psikologi antara turis dan tempat hingga tempat tersebut tidak lagi memiliki identitas sebagai informasi geografis [1]. Pada tingkat sosial, orang-orang akan menghadapi hal-hal yang menunjukkan keunikannya terhadap orang lain. Orang-orang merasa terancam dan 
mengakibatkan mereka terlibat dalam strategi koping kognitif dimana munculah perilaku untuk mengembalikan rasa kekhasan [20]. Prinsip kekhasan dipercaya dapat membentuk identitas dalam interaksi [21]. Maka dari itu dapat di simpulkan bahwa kekhasan suatu wilayah tidak hanya berpengaruh terhadap identitas kawasan tersebut, namun juga dapat berpengaruh terhdapat faktor sosial ekonomi masyarakat lokal. Hal ini menunjukkan bahwa kuat hubungannya antara kekhasan suatu kawasan yang dapat menjadi identitas diri wilayah tersebut terhadap manusia yang berada di kawasan tersebut. Dengan membandingkan teori utama identitas tempat: Breakwell dapat disimpulkan bahwa terdapat empat variabel yang dapat digunakan untuk menyelidiki aspek kekhasan suatu kawasan dalam menentukan identitas tempat kawasan tersebut, yaitu, (1) Landmark, (2) keunikan, dan (3) karakter tertentu, dan merekomendasikan (4) persepsi [6].

\section{Metodologi}

Tujuan dari paper ini adalah menemukan keterkaitan antar pariwisata berkelanjutan dan distinctiveness. Metode yang digunakan pada penelitian ini adalah tinjauan literatur teoritis yang berfokus pada kumpulan teori yang telah ditemukan pada penelitian sebelumnya sehubungan dengan masalah, konsep, teori, dan fenomena. Tinjaun ini kemudian menetapkan teori yang sudah ada, keterkaitan antar teori, sejauh mana teori tersebut telah dikaji dan kemudian mengembangkan sebuah teori baru. Kriteria teori yang digunakan pada penelitian ini yaitu sekitar 50\% teori diambil dari 5 tahun belakangan dan seluruhnya berasal dari jurnal-jurnal penelitian internasional yang berkaitan dengan pariwisata berkelanjutan dan distinctiveness. Berdasarkan hasil telaah teori, unutk menemukan keterkaitan antar aspek pariwisata berkelanjutan dan aspek distinctiveness tersebut digunakanlah bagan seperti dibawah ini (Gambar.1)

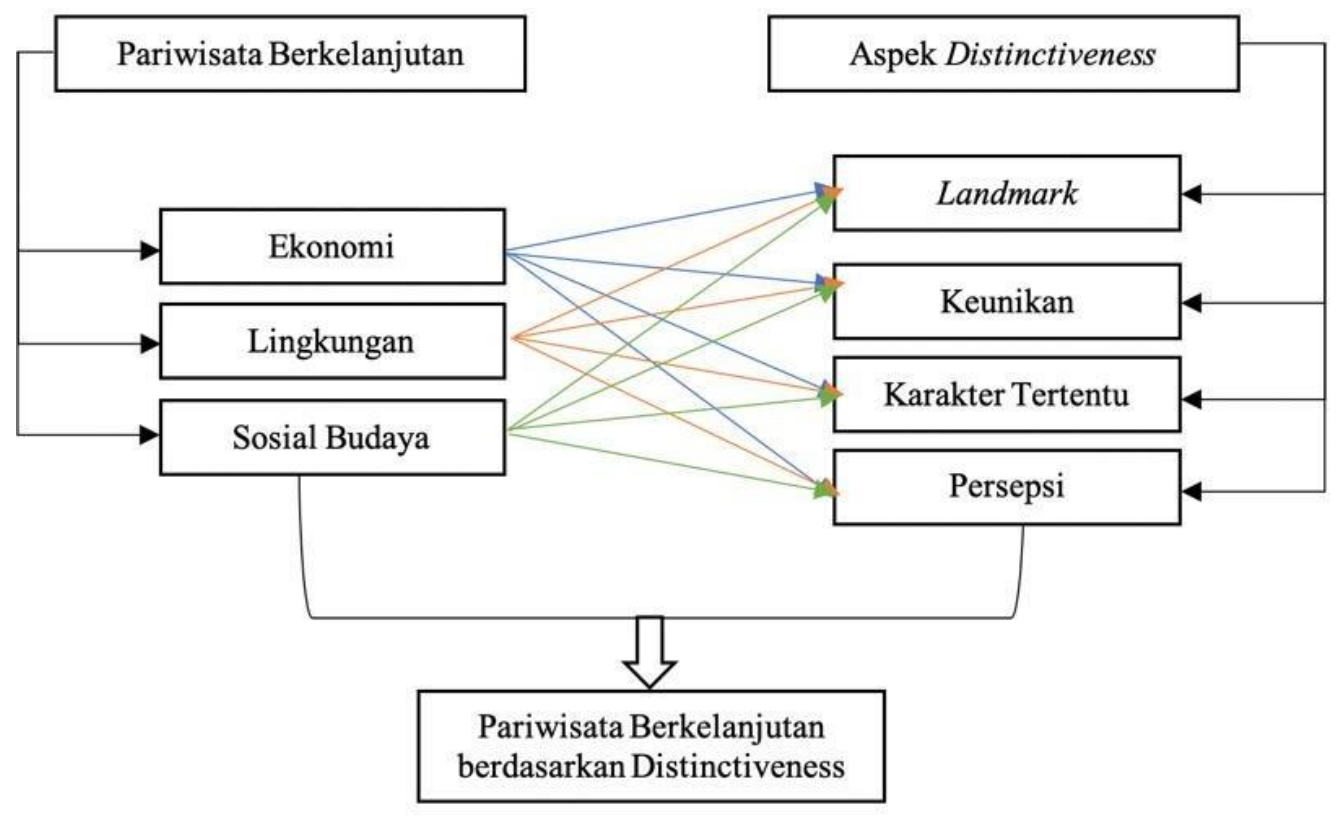

Gambar 1. Metode kajian teori pariwisata berkelanjutan berdasarkan distinctiveness

\section{Hasil danPembahasan}

\subsection{Kajian aspek ekonomi pariwisata berkelanjutan terhadap distinctiveness}

Pengembangan pariwisata berkelanjutan berdasarkan aspek ekonomi memiliki beberapa indikator penilaian, dimana indikator tersebut mencerminkan kontribusi pengembangan pariwisata berkelanjutan terhadap ekonomi lokal. Menurut penelitian sebelumnya indikator aspek ekonomi dalam pariwisata berkelanjutan antara lain sifat musiman dari perubahan alam, rasio jumlah wisatawan yang menginap dan akomodasi wisatawan, dan koefisien peningkatan pariwisata lokal 
[22]. Adapun indikator yang didapat dari penelitian lainnya aspek ekonomi pariwisata berkelanjutan adalah kenaikan harga fasilitas atau produk di daerah wisata, distribusi pendapatan dari pariwisata, adanya lapangan pekerjaan baru yang muncul di daerah wisata, dan penggunaan produk lokal yang khas, yang tidak hanya bagi wisatawan tetapi juga manfaat masyarakat setempat [23]. Dan dari penelitian selanjutnya yaitu manfaat pariwisata terhadap komunitas setempat dan daerah wisata, kepuasan wisatawan, kontrol pengembangan, fasilitas pariwisata yang ditawarkan penyediaan berbagai pengalaman, musiman kegiatan pariwisata, persentase kedatangan pengunjung, dan lapangan pekerjaan berkaitan dengan pariwisata yang merupakan indikator aspek ekonomi pariwisata berkelanjutan [24]. Dari beberapa penelitian sebelumnya tersebut indikator aspek ekonomi dapat disimpulkan menjadi lapangangan pekerjaan baru, dimana dengan adanya kebutuhan-kebutuhan baru yang muncul pada daerah wisata membuat tumbuhnya lapangan pekerjaan baru sebagai solusi pemenuhan kebutuhan, kemudian, persentase kedatangan pengunjung, hal ini mempengaruhi seberapa banyak keuntungan yang didapat dari banyaknya wisatwan baik keuntungan secara pribadi maupun umum, lalu fasilitas pariwisata yang ditawarkan, harga yang diberikan pada fasilitas di daerah wisata juga mampu memberikan keuntungan baik secara individual maupun kelompok, dan yang terakhir penggunaan produk lokal yang khas, penggunaan produk lokal mampu memberikan keuntungan bagi masyarakat setempat karna dapat meningkatkan perekonomian masyarakat.

Berdasarkan aspek distinctiveness, beberapa teori yang berkaitan dengan ekonomi telah di dapat dari penelitianpenelitian sebelumnya yaitu mengenai landmark dimana landmark merupakan suatu objek tiga dimensi yang lebih menonjol dibandingkan objek lainnya [25]. Landmark dengan visual yang menonjol memiliki pengaruh besar dalam mempromosikan kawasan [26]. Maka dari itu jumlah wisatawan yang mengunjungi kawasan pariwisata dipengaruhi oleh landmark. Kemudian mengenai keunikan suatu kawasan dimana etnis minoritas yang memiliki adat, tradisi, bahasa, dan gaya aristekturnya sendiri dapat menjadi nilai tambah bagi para wisatawan. Banyak wisatawan yang tertarik akan beragam budaya yang dihasilkan oleh kelompok minoritas [27]. Selain itu, ada tren yang berkembang untuk berpartisipasi dalam jenis pariwisata tertentu, terutama pariwisata sukarela, yang memungkinkan wisatawan untuk mengalami dan belajar secara unik dan melampaui platform pariwisata khas dari pengaturan yang dipentaskan dan terlibat dengan masyarakat lokal, kehidupan mereka, dan lingkungan hidup aktual [28]. Produk lokal yang menunjukkan karakteristik tempat yang berbeda dapat menjadi tanda bagi wisatawan ke tempat yang telah mereka kunjungi [29]. Halhal tersebut juga dapat menimbulkan ketertarikan wisatawan terhadap kawasan pariwisata.

Kemudian mengenai karakter tertentu dimana dikarenakan wisatawan yang lebih canggih, wisatawan mulai semakin mencari pengalaman perjalanan yang unik dan bermakna untuk memenuhi kebutuhan dan keinginan mereka [30]. Dalam hal ini, bangunan tradisional atau bangunan dengan tradisi khusus di suatu wilayah dimana kehidupan sehari- hari individu ditempatkan dapat menjadi karakter dari suatu daerah dan menarik para wisatawan untuk mengunjungi kawasan pariwisata. Kemudian mengenai perbedaan persepsi wisatawan antara satu dengan yang lainnya tentang suatu destinasi yang dapat mempengaruhi sifat dari wisatawan itu sendiri, apabila persepsi wisatawan positif maka wisatawan tersebut akan ingin datang kembali ke destinasi tersebut dan membicarakan hal mengenai destinasi ke orang-orang sekitarnya [31]. Persepsi yang positif inilah yang dapat meningkatkan jumlah wisatawan yang datang ke kawasan pariwisata.

Dari kedua teori aspek ekonomi pariwisata berkelanjutan dan distinctiveness tersebut ditemukanlah keterkaitan antar aspek ekonomi pariwisata berkelanjutan dan distinctiveness antara lain keberadaan landmark mampu mempromosikan kawasan tersebut sehingga menciptakan lapangan kerja baru, adanya landmark yang menarik perhatian dapat meningkatkan jumlah wisatawan yang datang, landmark pada kawasan dapat menjadi salah satu spot wisata, landmark yang ada pada kawasan di bangun menggunakan bahan-bahan lokal, keunikan destinasi yang dipromosikan dengan baik dapat menjadi sumber pendapatan kawasan, keunikan yang dimiliki kawasan dapat meningkatkan jumlah kedatangan pengunjung seiring berjalannya waktu, keunikan yang ada pada suatu kawasan dapat menjadi salah satu spot yang dapat di tawarkan, keunikan kawasan seperti budaya tetap mempertahankan penggunaan produk dan bahan lokal, pemeliharaan bangunan tradisional yang melibatkan masyarakat lokal,bangunan tradisional yang menarik minat dapat memberikan dampak positif bagi kedatangan pengunjung, bangunan tradisonal dapat menjadi salah satu spot paiwisata yang di tawarkan, bangunan tradisonal dibangun menggunakan bahan-bahan lokal yang terdapat di lingkungan sekitar, pandangan positif dari wisatawan dapat menciptakan destinasi wisata yang padat pengunjung, secara tidak langsung dapat menciptakan lapangan kerja bagi warga, pandangan positif dari wisatawan dapat meningkatkan persentase kedatangan wisatawan seiring berjalannya waktu, pandangan wisatawan terhadap baik dan buruknya fasilitas-fasilitas 
yang terdapat di kawasan, dan pandangan wisatawan terhadap penggunaan produk lokal yang masih digunakan padakawasan.

\subsection{Kajian aspek lingkungan pariwisata berkelanjutan terhadap distinctiveness}

Pengembangan pariwisata berkelanjutan berdasarkan aspek lingkungan memiliki beberapa indikator penilaian, dimana indikator tersebut mencerminkan kontribusi pengembangan pariwisata berkelanjutan terhadap lingkungan kawasan wisata. Menurut penelitian sebelumnya yang dikatakan sebagai indikator aspek lingkungan pariwisata berkelanjutan adalah landscape [32] [34], kualitas udara [32] [33] [34], dan kualitas air [32] [33] [34], tingkat kebisingan [33], dan kebersihan kawasan [33] [34], flora dan fauna [34], open space [34]. Dari beberapa penelitian sebelumnya tersebut indikator aspek lingkungan dapat disimpulkan menjadi landcape, dimana pemandangan danfaktor alamiah lainnya yang tersedia pada tiap-tiap kawasan adalah faktor utama yang dapat menonjolkan kawasan tersebut, kemudian kualitas air, kualitas air yang bersih dan penyaluran air yang baik ke seluruh kawasan dapat menunjang kemajuan pengembangan pariwisata kawasan, lalu kualitas udara, udara yang tersedia pada kawasan wisata sudah seharusnya terjaga dengan baik dan jauh dari polusi, dan yang terakhir kebersihan kawasan adalah salah satu faktor penting yang selain menunjang nilai pariwisata namun juga sangat membantu dalam menjaga kawasan tersebutkedepannya.

Berdasarkan aspek distinctiveness, beberapa teori yang berkaitan dengan lingkungan telah di dapat dari penelitian penelitian sebelumnya yaitu mengenai landmark dimana landmark adalah salah satu kunci elemen pembentuk image dan identitas lingkungan pariwisata [35]. Karakteristik landmark yang berbeda dari objek lainnya dapat membantu orang-orang untuk berorientasi dan mengakses tempat lainnya [35]. Selain itu juga dapat dilihat bahwa lokasi landmark sangat penting, jika besar atau tinggi, pengaturan ruang harus memungkinkannya untuk dilihat, jika kecil, ada zona tertentu yang menerima lebih banyak perhatian perseptual daripada yang lain, permukaan lantai, atau fasad didekatnya, atau sedikit dibawah, setinggimata. Dari teori tersebut dapat dilihat bahwa keterkaitan antara lingkungan dan landmark itu penting. Kemudian mengenai keunikan suatu kawasan dimana pandangan positif mengenai keunikan dan kegiatan yang hanya dapat dilakukan di tempat tertentu memengaruhi aspek kekhasan [7]. Hal ini sama dengan evaluasi eksternal karena evaluasi komparatif antara satu tempat dengan tempat lain, karakteristik tertentu dari suatu tempat, dan keunikan tempat seperti yang dirasakan oleh masyarakat [7]. Keunikan sebuah tempat dapat membantu seseorang untuk mngeorientasikan tempat tersebut dan memberikan kenyamanan sehingga orang-orang dapatmerasa terhubung dengan tempat tersebut. Maka dari itu, karakter-karakter tempat yang berbedalah yang memunculkan keunikan itu sendiri [1]. Disini dapat dilihat bagimana lingkungan mempengaruhi keunikan di tiap-tiap kawasan wisata. Kemudian mengenai karakter tertentu dimana tempat merupakan suatu proses pengalaman yang membentuk identitas dan karakter tempat yang khas [36]. Karakter khusus kawasan wisata dapat memberi manfaat dan seimbang ke tempat itu [37]. Bangunan-bangunan tradisional dalam sebuah kelompok memiliki kontribusi dalam menanamkan identitas unik dari lingkungan pariwisata dan membawa karakteristik arsitektur dari periode yang dibangun yang memberikan kontinuitas budaya kota itu, menciptakan identitas dan meneruskannya ke generasi berikutnya [38]. Berdasarkan teori tersebut dapat disumpulkan bahwa banguna-bangunan tradisional dibangun dengan karakter yang telah disesuaikan dengan lingkungan alam sekitar. Kemudian mengenai perbedaan persepsi dimana setiap wisatawan memiliki persepsi yang berbeda yang disebabkan oleh sikap lingkungan dan kawasan terkait, dan juga karena karakteristik profil pengunjung kawasan [39]. Dalam hal pariwisata, wisatawan peduli pada konteks persepsi yang berkaitan dengan misalnya, pola sumber daya alam didistribusikan di seluruh lanskap dan wisatawan lebih tertarik pada daya tarik alami aktual yang terkait dengan pengalaman rekreasi mereka daripada dalam dampak lingkungan potensial terkait [40]. Dari teori tersebut dapat dilihat bahwa ketertarikan wisatawan terhadap lingkungan sekitar kawasan wisatawan juga berpengaruh dalam pariwisata berkelanjutan.

Dari kedua teori aspek lingkungan pariwisata berkelanjutan dan distinctiveness tersebut ditemukanlah keterkaitan antar aspek ekonomi pariwisata berkelanjutan dan distinctiveness antara lain tata letak landmark dapat dipengaruhi oleh pemandangan/landscape kawasan, landmark yang terjaga kebersihannya dapat meningkatkan kenyamanan dan kepuasan wisatawan, keunikan budaya lokal berkembang mengikuti situasi dan kondisi alam, keunikan budaya lokal dapat mempengaruhi kualitas air sekitarnya, apabila kegiatan budaya terkait dengan sumber air kawasan, keunikan budaya lokal dapat mempengaruhi udara misalnya asap, dupa, dan lain-lain, keunikan budaya lokal yang dapat berjalan tanpa merusak lingkungan sehingga berdampak positif bagi semua pihak, bangunan tradisional pada kawasan bisa saja 
dibangun berdasarkan pertimbangan/kesesuaian dengan keadaan alam kawasan, bangunan tradisional yang dijaga kebersihannya agar menarik wisatawan, pandangan wisatwan terhadap pemandangan alam/landscape pada kawasan, pandangan wisatawan terhadap ketersediaan air bersih pada kawasan, pandangan wisatawan terhadap kualitas udara pada kawasan, dan pandangan wisatawan terhadap tingkat kebersihan kawasan.

\subsection{Kajian aspek lingkungan pariwisata berkelanjutan terhadap distinctiveness}

Pengembangan pariwisata berkelanjutan berdasarkan aspek sosial budaya memiliki beberapa indikator penilaian, dimana indikator tersebut mencerminkan kontribusi pengembangan pariwisata berkelanjutan terhadap sosial budaya lokal. Penelitian sebelumnya mengakatakan desa-desa tradisonal [41], etnis dan bahasa [41] [42] [43], dan tempat yang belum tersentuh [41], pendidikan [42], nilai budaya dan kesenian[42][43], kondisi sosial masyarakat [42] [43],

dan tempat tinggal [43] merupakan indikator aspek sosial budaya pariwisata berkelanjutan. Dari beberapa penelitian sebelumnyatersebutindikatoraspeksosialbudayapariwisataberkelanjutandapatdisimpulkanmenjadilayanganyang ditawarkan, yaitu layanan yang berupa akses menuju suatu tempat tradisional ataupun ciri khas pada satu daerah, kemudian nilai budaya dan kesenian, berupa nilai-nilai peninggalan sejarah satu daerah. Untuk memperkuatnya, hal ini berhubungan dengan tradisi yang dilakukan oleh orang lokal. Bisa itu tarian tradisional, musik tradisional, maupun festival atau perayaan yang diadakan, lalu etnis dan bahasa, yaitu produk lokal yang di jual toko-toko tradisional mampu memberikan ciri khas budaya pada suatu daerah dan adapula bahasa yang digunakan pada satu daerah berbeda dengan daerah lainnya, dan yang terakhir kondisi sosial msyarakat, hal ini menunjukkan interaksi akan satu daerah antar orang lokal dan turis dan bagaimana orang lokal menyikapi turis, bisa itu berupa senyuman, sapaan maupun hormat.

Berdasarkan aspek distinctiveness, beberapa teori yang berkaitan dengan sosial budaya telah didapat dari penelitian penelitian sebelumnya yaitu mengenai landmark dimana atribut landmark menggambarkan hal yang meliputi skala, proporsidanukuran,warna,singularitas/keunikan/berbeda/kontras,lokasi/posisistrategis,ornamen/detail[35].Selain itu, landmark juga mempengaruhi ingatan seseorang terhadap suatu tempat [35]. Dapat dilihat bahwa landmark dipengaruhi oleh budaya sekitar. Kemudian mengenai keunikan suatu kawasan dimana sekelompok orang dapat memberikan kontribusi penting ke tempat-tempat wisata di sebuah kawasan ketika rincian tentang keunikan mereka ditawarkan kepada konsumen sebagai informasi tambahan dan nilai budaya. Berdasarkan variasi ini, area yang menampung budaya minoritas dapat menjadi tujuan objek wisata dengan memperkaya kontennya. Cara hidup yang berbeda dari populasi mayoritas, sistem nilai baru, perilaku sosial lainnya, dan keunikan budaya sekelompok individu membentuk aset tak berwujud yang menjadi daya tarik. Dengan demikian, mereka dapat menjadi faktor daya tarik bagi pariwisata, seperti halnya benda budaya secara fisik [27]. Dinamika budaya dan warisan telah memberikan makna khusus dalam jiwa wisatawan bahkan hanya melalui makanan tradisional [19]. Dapat disimpulkan bahwa keunikan suatu kawasan banyak dipengaruhi oleh budaya kawasan itu sendiri. Kemudian mengenai karakter tertentu dimana jika suatu tempat menarik dan dapat dikenali, karakter khusus suatu tempat akan berbeda dengan tempat lain. Terlihat juga dari budayanya yaitu melalui kegiatan, produk lokal, transportasi, dan bangunan [1]. Bangunan tradisional atau bangunan dengan tradisi khusus di suatu wilayah dimana kehidupan sehari-hari individu ditempatkan dapat menjadi karakter dari suatu daerah [38]. Atribut bangunan tradisional dan gaya arsitektur merupakan bagian dari "budaya" yang harus dipahami di tempat tersebut [44]. Deretan fasad bangunan yang berhasil memberikan kenyamanan visual di kawasan cagar budaya tentu akan memengaruhi pembentukan identitas tempat. Fasad dengan elemen visual yang menghasilkan sebuah identitas mampu memikat wisatawan [19]. Agar dapat memberikan pengalaman yang unik, haruslah terlebih dahulu untuk mengidentifikasi dan menyoroti aspek paling signifikan dari budaya destinasi, sejarah, dan cara hidup lokal yang membedakannya dari yang lain dunia pariwisata [9]. Maka dari itu dapat dilihat bangunan- bangunan tradisional yang tentunya terpengaruh oleh budaya lokal juga banyak mempengaruhi kedatangan wisatawan ke kawasan wisata. Kemudian mengenai perbedaan persepsi dimana pemangku kepentingan, termasuk para ilmuwan yang sangat terlatih, juga mengemukakan persepsi dan pemahaman mereka yang merefleksikan latar belakang sosial dan budaya mereka [39]. Dapat disimpulkan bahwa pandangan masyarakat terhadap budaya lokal meningkatkan minat wisatawan terhadap kawasanwisata.

Dari kedua teori aspek sosial budaya pariwisata berkelanjutan dan distinctiveness tersebut ditemukanlah keterkaitan antar aspek sosial budaya pariwisata berkelanjutan dan distinctiveness antara lain landmark dapat menjadi salah satu 
pusat penanda kawasan, bentuk dan motif landmark dapat terpengaruh atas nilai-nilai budaya dan kesenian warga lokal, landmark dapat dipengaruhi oleh etnis lokal dan juga bahasa lokal yang digunakan, landmark dapat menjadi salah satu media untuk timbulnya interaksi antara masyarakat lokal dengan wisatawan, keunikan budaya lokal dapat menciptakan layanan seperti hostel dengan bangunan bergaya lokal, keunikan budaya lokal kuat hubungannya dengan nilai-nilai budaya dan kesenian kawasan, keunikan budaya lokal erat kaitannya dengan etnis dan juga Bahasa yang digunakan oleh masyarakat sejak lama, keunikan budaya lokal dapat menimbulkan bagaimana sikap masyarakat lokal terhadap wisatawan, bangunan tradisional dapat dijadikan sebagai tempat penginapan, bangunan tradisional erat kaitannya dengan nilai-nilai budaya dan kesenian yang ada, bangunan tradisional berhubungan kuat dengan etnis lokal dan juga bahasa yang berkembang, bangunan tradisonal dapat menjadi salah satu cara untuk lebih mengetahui kehidupan masyarakat lokal, pandangan wisatawan terhadap layanan yang disediakan masyarakat, pandangan wisatawan terhadap nilai-nilai budaya dan kesenian kawasan, psndangan wisatawan terhadap etnis dan bahasa lokal dan pandangan wisatawan terhadap bagaimana masyarakat lokal berinteraksi kepadawisatawan.

\section{Kesimpulan}

Selain menjadi sebuah destinasi wisata, pariwisata juga merupakan simbol dan faktor penting untuk membangun serta menyampaikan rasa identitas nasional [2]. Saat ini pariwisata menggunakan prinsip pariwisata berkelanjutan untuk memperhitungkan dampak sosial, lingkungan dan ekonomi baik saat ini maupun masa depan, menangani kebutuhan pengunjung, industri, lingkungan dan masyarakat lokal [3]. Prinsip keberlanjutan mengacu pada aspek (1) ekonomi, (2) lingkungan, dan (3) sosial budaya dari pengembangan pariwisata [4]. Salah satu elemen identitas tempat, yaitu distinctiveness, digunakan dalam penelitian ini sebagai penunjang pariwisata berkelanjutan. Distinctiveness merupakan aspek penting dalam mengembangkan keunikan suatu tempat [7]. Distinctiveness mengacu pada wilayah atau tempat yang dapat dibedakan dari tempat dan atau kota lainnya [6]. Terdapat empat aspek distinctiveness yaitu

(1) landmark, (2) keunikan, (3) karakter tertentu, dan (4) perbedaan persepsi. Pada penelitian ini keterkaitan aspek pariwisata berkelanjutan dan aspek distinctiveness dapat dilihat pada bagan berikut (Gambar.2). Hasil dari penelitian ini sekiranya dapat digunakan sebagai landasan literatut kajian pariwisata berkelanjutan dan secara prakteknya dapat digunakan oleh para stakeholder untuk pemgembangan pariwisata berkelanjutan berdasarkan aspek distinctiveness.

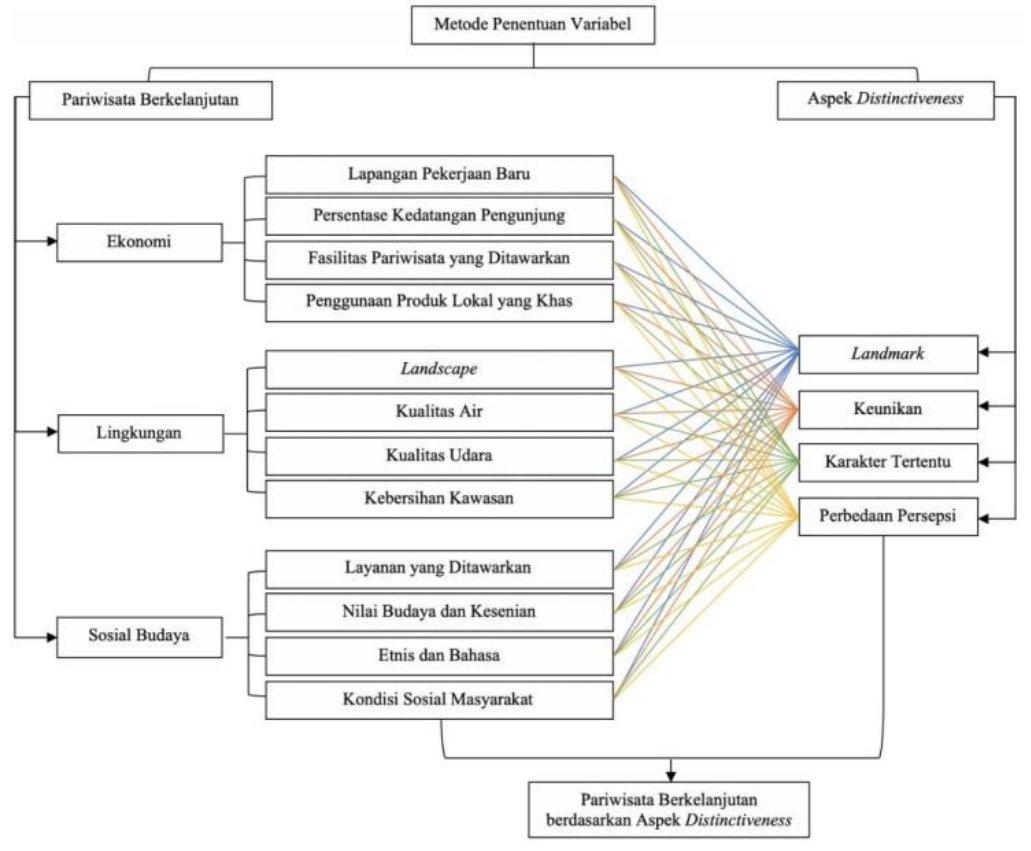

Gambar 2. Keterkaitan aspek pariwisata berkelanjutan dan distinctiveness. 


\section{Referensi}

[1] Ginting, N., Nasution, A. D., Rahman, N. V. (2017). More Attractive More Identified: Distinctiveness in Embedding Place Identity. Procedia Environmental Sciences, 37,408-419.

[2] Palmer, C. (1999). Tourism and Symbol of Identity. Tourism Management. 20,313-322.

[3] UNWTO. (2012). Sustainable development of tourism: Definition. Retrieved from http://sdt.unwto.org/en/content/about-us-5. In Tyrväinen, L.,Uusitalo,M.,Silvennoinen,H.,\&Hasu,E.(2014).Towardssustainablegrowthinnature-basedtourismdestinations:Clients'viewsofland use options in Finnish Lapland. Landscape and Urban Planning, 122,1-15.

[4] UNEP and UNWTO. (2005). Making Tourism More Sustainable. A guide for policy makers.11-12

[5] Ginting, N., Rahman, N. V., Nasution, A. D. (2017). Increasing Tourism in Karo District, Indonesia Based on PlaceIdentity.

[6] Twigger-Ross, C. L., \& Uzzell, D. L. (1996). Place and Identities Process. Journal of Environmental Psychology, 16(3), 205-220. https://doi.org/10.1006/jevp.1996.0017.

[7] Lalli,M.(1992).Urban-RelatedIdentity:Theory,Measurement,andEmpiricalfindings.JournalofEnvironmentalPsychology,12(4),285303. https://doi.org/10.1016/S02724944(05)80078-7 [8] Palmer, C. (1999). Tourism and Symbol of Identity. Tourism Management. 20, 313322.

[8] Wang, S., \& Xu, H. (2015). Influence of place-based senses of distinctiveness, continuity, self-esteem and self-efficacy on residents' attitudes toward tourism. Tourism Management, 47,241-250.

[9] Kim, J. (2014). The Antecedents of Memorable Tourism Experiences: The Development of a Scale to Measure The Destination Attributes Associated with Memorable Experiences. Tourism Management, 44, 34-45.

[10] Qu,H.,Kim,H.L.,\&Im,H.H.(2011).AModelofDestinationBranding:IntegratingTheConceptsofTheBrandingandDestinationImage. TourismManagement,32(3),465-476.InTruong,T.L.H.,Lenglet,F.Mothe,C.(2017).DestinationDistinctiveness:Concept,Measurement, Impact on TourismSatisfaction.

[11] Middleton, V.T.C., Fyall, A., Morgan, M. \& Ranchhod, A. (2009). Marketing in travel and tourism.4.

[12] Eccles. (1995). Marketing, Sustainable Development and International Tourism International. Journal of Contemporary Hospitality Management, 7, 20-26. In Juandi, V. S., Andari, R., Setiyorini, H. P. D. (2017). The Influence of Sustainable Tourism Development towards Tourists' Satisfaction in Saung Angklung Udjo.

[13] Wiwattanakantang.,To-im.(2014).TouristSatisfactiononSustainableTourismDevelopmentAmphawaFloatingMarket,SamutSongkhram, Thailand. In Juandi, V. S., Andari, R., Setiyorini, H. P. D. (2017). The Influence of Sustainable Tourism Development towards Tourists' Satisfaction in Saung AngklungUdjo.

[14] Jiaying,L.,Sanjay,K.(2009).Sustainabletourismresearch:ananalysisofpaperspublished.JournalofSustainableTourism,17:1,5-16,DOI: $10.1080 / 09669580802582480$.

[15] Hughes, G. (1995). The Cultural Construction of Sustainable Tourism. Tourism Management. 16 (1),49-59.

[16] Blancas,F.J.,Lozano-Oyola,M.,González,M.,Guerrero,F.M.,Caballero,R.,(2011).Howtousesustainabilityindicatorsfortourismplanning: the case of rural tourismin Andalusia (Spain). Sci. Total Environ. 412,28-45.

[17] Choi, H. C., \& Sirakaya, E. (2006). Sustainability indicators for managing community tourism. Tourism management, 27(6),1274-1289.

[18] Astawa, I. P., Triyuni, N. N., Santosa, I. D. M. C. (2018). Sustainable tourism and harmonious culture: a case study of cultic model at village tourism

[19] Ginting, N., Wahid, J. (2016). Defining Distinctiveness Aspect of Place Identity in Urban HeritageTourism.

[20] Branscombe, N. R., Ellemers, N., Spears R., \& Doosje, B. (1999). The Context and Content of Social Identity Threat. In N., Ellemers, R. Spears,\&B.Doosje(Eds.),Socialidentity:Context,commitment,content(pp.35-58).Oxford,UK:Blackwell.InLessem,E.(2006).Strategies of Differentiation: Preferences in Context of Upward or Downward Comparisons and Cooperation orCompetition.

[21] Breakwell, G. M. (1993). Social representations and social identity. Papers on Social Representations, 2, 198-217. In Vignoles, V. L., Chryssochoou, X., Breakwell, G. M. (2000). The Distinctiveness Principle: Identity, Meaning, and The Bounds of Cultural Relativity. Personality and Social Psychology Review, 4,337-354.

[22] Burghelea, C., Uzlău, C., \& Ene, C. M. (2016). Comparative indicators of sustainable tourism. Scientific Papers. Series" Management, Economic Engineering în Agriculture and rural development, 16(3),77-80.

[23] Cottrell, S., Van der Duim, R., Ankersmid, P., \& Kelder, L. (2004). Measuring the sustainability of tourism in Manuel Antonio and Texel: A tourist perspective. Journal of Sustainable Tourism, 12(5),409-431.

[24] Lozano-Oyola, M., Blancas, F. J., González, M., \& Caballero, R. (2012). Sustainable tourism indicators as planning tools in cultural destinations. Ecological Indicators, 18,659-675.

[25] Shuhana, S. (2011). Townscape Revisited: Unravelling the character of the Historic Townscape in Malaysia. In Hussain, K. A. M., Ujang, N. (2014). Visitors' Identification of Landmarks in The Historic District of Banda Hilir, Melaka,Malaysia.

[26] Riza, M., Doratli, N., \& Fasli, M. (2012). City Branding and Identity. Social and Behavioral Sciences. 35,293-300.

[27] Pechlaner, H. (2011). Enhancing tourism destinations through promoting the variety and uniqueness of attractions offered by minority populations: an exploratory study towards a new research field. Tourism Review, 4, 54-64.http://dx.doi.org/10.1108/16605371111188740

[28] Brown, S. (2005). Travelling with a Purpose: Understanding The Motives and Benefits of Volunteer Vacationers. Current Issues in Tourism, 8(6), 479e496. In Kim, J. H. (2014). The Antecedents of zMemorable Tourism Experiences: The Development of Scale to Measure The Destination Attributes Associated with Memorable Experiences. Tourism Management, 44,34-45.

[29] Kastenholz, E., Eusébio, C., \& Carneiro, M. J. (2016). Purchase of local products within the rural tourist experience context. Tourism Economics, 22(4),729-748.

[30] Hall, C., \& Weiler, B. (1992). What's special about special interest tourism. In B. Weiler, \& C. M. Hall (Eds.), Special interest tourism (pp. 1e14).NewYork:Wiley.InKim,J.H.(2014).TheAntecedentsofzMemorableTourismExperiences:TheDevelopmentofScaletoMeasure The Destination Attributes Associated with Memorable Experiences. Tourism Management, 44,34-45.

[31] Konecnik,M.(2006).Croatian-basedbrandequityforSloveniaasatourismdestination.EconomicandbusinessreviewforCentralandSouth- Eastern 
Europe, 8(1), 83.

[32] Spenceley,A.(2005).Nature-basedtourismandenvironmentalsustainabilityinSouthAfrica.JournalofSustainableTourism,13(2),136-170.

[33] Mihalič,T.(2000).Environmentalmanagementofatouristdestination:Afactoroftourismcompetitiveness.Tourismmanagement,21(1),65- 78.

[34] Inskeep, E. (1991). Tourism planning: an integrated and sustainable development approach. Van NostrandReinhold.

[35] Hussain,K.A.M.,Ujang,N.(2014).Visitors'IdentificationofLandmarksinTheHistoricDistrictof BandaHilir,Melaka,Malaysia.

[36] Ujang, N., \& Zakariya, K. (2015). The notion of place, place meaning and identity in urban regeneration. Procedia-social and behavioral sciences, 170,709-717.

[37] Marpaung,B.O.(2016).CommunicationStrategyPlanningofFishermanKampungMedanBelawanasaTouristDestination.Procedia-Social and Behavioral Sciences, 234,344-352.

[38] Yaldiz, E., Aydin, D., Siramkaya, S.B. (2014). Loss of City Identities in The Process of Change: The City of Konya-Turkey. Social and Behavioral Sciences. 140,221-233.

[39] Petrosillo, I., Zurlini, G., Grato, E., \& Zaccarelli, N. (2006). Indicating fragility of socio-ecological tourism-based systems. Ecological Indicators, 6(1),104-113.

[40] Davidson-Hunt, I., \& Berkes, F. (2003). Learning as you journey: Anishinaabe perception of social-ecological environments and adaptive learning. Conservation Ecology,8(1).

[41] Mbaiwa, J. E. (2004). The success and sustainability of community-based natural resource management in the Okavango Delta, Botswana. South African Geographical Journal, 86(1),44-53.

[42] Waani, H. F. (2016). Sosial Budaya Dalam Pengembangan Pariwisata Di Kelurahan Bunaken Kecamatan Bunaken Kota Manado. ACTA DIURNA KOMUNIKASI,5(2).

[43] Cole, S. (2007). Beyond authenticity and commodification. Annals of Tourism Research, 34(4),943-960.Kianicka, S., Buchecker, M., Hunziker, M., \& Müler-Böker, U. (2006). Locals' and Tourists' Sense of Place. Mountain Research and Development, 26(1), 55-63, doi: 10.1659/0276-4741(2006)026[0055:LATSOP]2.0.CO;2. In Ginting, N., Nasution, A. D., Rahman, N. V. (2017). More Attractive More Identified: Distinctiveness in Embedding Place Identity. Proc 